\title{
Immigration and occupational status in economic crisis*
}

\author{
Alfonso Arellano \\ Universidad Complutense y \\ Fundación de Estudios de Economía Aplicada (FEDEA)
}

\begin{abstract}
The type of employment is an important aspect of the immigrant labour market experience. Using data from the CSWH in 2008 and 2012, the study shows the differences between selfemployment and paid-employment among groups of immigrant and native workers.In 2008, men from North America, Asia and Oceania, and Europe selected the first option. The comparison of the results between 2008 and 2012 suggests robustness in the qualitative conclusions between native and immigrant workers only in general terms. In 2012, those immigrants who were more likely to be self-employed belong to North America, Asia and Oceania, and the EU-15, regardless of the gender. Therefore, there is also a gender effect on the type of job selected, as well as the influence of institutional factors and the difficult economic environment in this aspect. These results confirm the importance of the "structuralist" and the "cultural" factors in the occupational status selection process.
\end{abstract}

Keywords: self-employment, paid employment, immigrant worker, economic crisis

JEL classification: J15, J16, J61, J62 .

\section{Resumen}

El tipo de empleo es un aspecto importante de la experiencia laboral del inmigrante. Utilizando datos de la MCVL en 2008 y 2012, el estudio muestra las diferencias entre el trabajo por cuenta propia y por cuenta ajena entre grupos de trabajadores inmigrantes y nativos. En 2008, los varones de Norteamérica, Asia y Oceanía, y Europa seleccionaban la primera opción. La comparación de los resultados entre 2008 y 2012 sugiere robustez en las conclusiones cualitativas entre trabajadores nativos e inmigrantes sólo en términos generales. En 2012, los inmigrantes más propensos a ser trabajadores por cuenta propia pertenecen a Norteamérica, Asia y Oceanía, y la UE-15, con independencia de su género. Por tanto, hay un efecto de género en el tipo de trabajo seleccionado, así como la influencia de los factores institucionales y del difícil entorno económico en este aspecto. Estos resultados confirman la importancia de los factores "estructurales" y "culturales" en el proceso de selección de la situación ocupacional.

Palabras clave: empleo por cuenta propia, empleo por cuenta ajena, trabajador inmigrante, crisis económica

Clasificación JEL: J15, J16, J61, J62.

* The author is grateful to an anonymous referee for providing insightful comments and suggestions on a previous draft of this paper. The usual disclaimer applies. 


\section{Introduction}

Over the years corresponding to the economic boom between 1996 and 2007, an important number of foreign workers was joined into the labour market by breaking with the image of Spain as a source of emigration. In the last two decades, the labour and demographic structure of Spain has changed in depth.

The labour force in Spain has been negatively conditioned by the economic crisis which began at the end of 2007 and has generated dramatic effects on employment since 2008. Regardless of the causes that underlie the economic crisis, the labour market situation in Spain is more complex than that experienced between 1993 and 1994, the previous economic crisis. One of the factors increasing the complexity of the system lies in the largest participation of foreign-born workers who have joined the Spanish economy. Using data from the Spanish Labour Force Survey (EPA), elaborated by the National Statistics Institute (INE), the number of immigrant workers grew from 196,500 in the first quarter of 1998 to near three million $(2,947,900)$ in the third quarter of 2008 (EPA, INE). This population has declined in the last years up to $2,013,500$ workers in the fourth quarter of 2013, although they still represent above $10 \%$ of the total workforce.

The economic crisis has reduced the labour force near 17\% in the period 2007-2013. The destruction has been assymetric by gender and nationality, affecting to foreign male workers more deeply. The type of employment has not been affected equally by the crisis either. The number of self-employed workers has grown $11 \%$ for foreign people between 2007 and 2013, increasing the weight of women above $31 \%$ while men only increase the group by one percent. The number of native self-employed workers has been reduced by near $20 \%$ for men and below $14 \%$ for women (EPA, INE).

The study by Lacuesta and Puente (2010) notes that the entry of foreign workers is more sensitive to economic growth than outflows. The outflows depend more on the relationship between the Gross Domestic Product (GDP) of the origin and the host country. In this period of economic crisis, the input of immigration has been drastically reduced, but the output has not experienced great movements, so this excess of labour supply is facing a very difficult working environment. The immigrant's return to the home country is largely motivated by a lack of versatility of the labour market and the ability to conform to economic changes. In addition to geographic mobility, occupational mobility and entrepreneurship constitute an alternative way.

In order to avoid a massive loss of productive factors, it is necessary to know and understand how the ability of workers to get a job and create new employment options is adjusted to the new macroeconomic environment. The objective of this study is manifold: first, the research aims to determine whether there are differences between immigrant and native workers choosing occupational status: self-employment or paid employment. The second objective is to identify among immigrant workers if there is a heterogeneous answer to the selection of occupational status. Finally, the study also tries to analyse the effect of the duration and intensity of the economic crisis, as well as other factors associated to the worker on these decisions. 
The results confirm the existence of a different behaviour between immigrant and native workers in terms of occupational status, and these behaviour changes between 2008 and 2012. The results in 2008 show that those men from North America, Asia and Oceania, and Europe selected self-employment as first option. In 2012, those immigrants who were more likely to be self-employed belong to North America, Asia and Oceania, and the EU-15, regardless of the gender. From these conclusions, the gender effect is also a relevant factor in this kind of labour market decision.

The estimates also suggest the workers consider the selection of indefinite duration contract versus fixed-term contract as relevant as the dichotomy self-employment/ paid employment. Moreover, there is a high level of heterogenerity among the subgroups of immigrant workers by nationality, affected by the importance of the "structuralist" and the "cultural" factors in the selection process of the occupational status. An interesting example is the comparison of the results between the workers from the last countries in the Eastern Europe incorporated to the EU and those workers from North America, Asia and Oceania.

The paper is structured as follows: Section 2 describes the pattern of immigrant workers and their relationship with self-employment. Section 3 dezscribes the database used in the paper. The parametric modelling is explained in Section 4. Section 5 presents the results of the models. Finally, the main conclusions are incorporated in Section 6.

\section{Self-employment and immigrants}

One of the objectives of this paper is to establish whether there are different behaviour patterns among immigrants and natives (and among several immigrant groups as the data allow the distinction) in the selection process between paid employment and self-employment and discover, if any, the mechanisms behind this process, taking into account the recent economic context. This section provides additional information in order to understand the results.

The definition of immigrant used in this research is based on the citizenship/ nationality of the individual, and not in the country of birth, following the same strategy as in other documents elaborated in Spain, like Izquierdo, Lacuesta and Vegas (2009), and the legislation established to get the Spanish nationality. There are multiple ways, but the citizenship is mainly based on the origin (at least one of the parents has the Spanish nationality), as determined by the Civil Code.

The relationship between immigration and self-employment on the Spanish labour market has been studied considering many aspects and approaches. Solé, Parella and Cavalcanti (2007) identify the factors that allow some ethnic groups to develop entrepreneurial activities more easily than others do, and how the employment decisions of immigrant workers are affected by the situation of the host country.

The identification process in this paper does not try to distinguish an unobservable characteristic such as entrepreneurship, because the sample does not provide 
perfect information in order to establish one-to-one correspondence between selfemployment and entrepreneurship, as all self-employed workers do not carry out a business and vice versa. Beyond this aspect, immigrant workers tend to be more proactive and less averse to change, as evidenced by the change of country to find work opportunities (Borjas, 1986).

The conditions of the host country (through sectors and other institutional factors) determine the initiative, and immigrant workers eventually end up adapting the same preferences as native workers have. Despite the crisis, this factor is meant neither to be oversized nor merely to adopt a "structuralist" point of view (based on the economic environment of the host country). The "cultural" factors (focused on the cultural background of the foreign workers) also constitute an element of explanation in the entrepreneurial initiatives of immigrants. Instead of these two interpretations (the first one is followed by Brunet and Alarcon, 2005, and the second explanation is considered by Light, 1972, and Zhou, 1992, among others), this document aims to combine both of them, following an interactive approach recommended by Waldinger, Aldrich and Ward (1990).

Institutional factors are also relevant in the job selection process. As suggested by Arellano (2010a, 2010b), the percentage of employees between natives and immigrants varies over time, especially as the immigrants have recently joined the host country. Even within the immigrants themselves, there are also important differences, partially due to the moratorium established by the Spanish government (as governments in other countries of the EU-15 also did) between 2007 and 2009 on the last countries in the Eastern Europe incorporated to the EU. The measure limited the entry of citizens of Romania and Bulgaria, as previously occurred when ten countries joined in 2004 with the enlargement of the EU-25. These entry restrictions were focused only on employees.

Another question remaining out of the analysis are the potential transnational connections that foreign individuals may use between the host country and the home country for the benefit of their own work activities. The database used in this study does not allow the analysis of industrial relations in detail and contacts outside Spain. In this sense, the results should be taken into account considering these limitations.

\section{Database}

According to the study of Solé, Parella and Cavalcanti (2007), the statistics on foreign workers affiliated to the Social Security are a leading data source to analyse quantitatively the phenomenon of self-employment among immigrants in Spain. They also point out as alternatives to this issue the Statistical Yearbook of Immigration and the Yearbook of Labour Statistics and Social Affairs, both published by the Ministry of Labour and Immigration. This paper uses a different microdata source from the Ministry of Labour and Immigration: the Continuous Sample of Working Histories 
(CSWH, "Muestra Continua de Vidas Laborales" in Spanish) provided by the Social Security.

The CSWH has the complete history of affiliation records of the Social Security for workers living in Spain. It includes a simple random selection of those people who had an affiliation in the Social Security in the reference year. The sample size amounts four percent of the total population in databases of the Social Security.

The information of the CSWH corresponds to the union of the Social Security administrative records, the Municipal Continuous Register of Inhabitants and fiscal registers. The available information from the Social Security belongs to several areas: details on labour market history, perception of contributory benefits (if any), personal characteristics and tax information. The CSWH has a small amount of dropouts derived from the heterogeneity of the sources of information. The observations with incomplete information are excluded from the analysis.

The information provided by the tax data file comes from the details contained in the part related with the deductions and payments on account of the personal income tax. This file includes employees primarily, but self-employed workers are not very well represented. Consequently, those variables included in this file are not considered to prevent the inclusion of unobserved heterogeneity in the sample and affect the external validity of the results negatively, as well as reduce the importance of self-employment in the economy.

Apart from the wealth of information, the main advantage of the CSWH for the purpose of the paper is the number of observations of two important target groups of individuals: the immigrant collective and the self-employed workers. However, those included in the CSWH only represent the "formal" economy. The conclusions do not take into account the effect of the underground economy. This caveat may be important as the weight of illegal immigrants in the labour market is high. The problem is not very relevant for workers from the EU. The effect may be important for those who come from other geographic areas, specially where migration pressure is affected by severe difficulties in the origin country.

A problem caused by the structure of the CSWH is associated with the complexity and dynamism of the labour market in Spain. The observation of reference in the CSWH is not the individual, but the labour market relationship (or situation) with the Social Security. Besides workers who have a single job throughout their working life, there are other individuals who experience a great turnover of jobs, and sometimes combine several positions at once. In the first case, there exists only one observation per individual. In the second case, there are as many observations as labour market transitions the individual has.

The selection of observations within the CSWH is based on three situations as occupied: self-employment, paid employment with a fixed-term contract and paid employment with an indefinite duration contract. The definitions of self-employed worker, temporary worker and permanent worker depend on the contribution system the individual belongs to and the type of employment relationship. The information on the contribution system comes from the registration form in the databases of 
the Social Security. This information is maintained while the worker's employment relationship lasts. The type of employment relationship identifies people who are contributors with their specific peculiarities.

The sample used in the estimation process resumes the information in such a way that there is a one-to-one relationship between situation (contract / self-employment) and individual. The worker is identified with the characteristics of the last labour market situation in the reference year. Whether the worker has multiple relationships (moonlighting), the main employment position (defined as the oldest one) is selected. The process is similar to that explained in Sánchez-Moral, Méndez and Arellano (2014). Two sets of the CSWH are used, corresponding with two reference years, 2008 and 2012. The year 2008 corresponds to the first complete recession year and the period with the maximum value of immigrant workers in Spain (EPA, INE). The last available information of the CSWH corresponds to 2012.

The CSWH provides individual labour market transitions up to the end of the reference year. In order to avoid problems related to time, as well as the difficulties associated with data management, the research focuses on labour market histories during the reference year. The unobserved heterogeneity derived from the economic cycle is expected not to affect the conclusions of the analysis deeply, because the amount and type of labour market transitions depend on the economic cycle, as the use of the CSWH suggests comparing the number of observations between 2008 and 2012.

Table 1 provides a set of descriptive statistics for occupied workers in both reference years. The subsample used from the CSWH with complete information includes 768,661 workers in 2008 and 703,119 workers in 2012, divided by gender. This process shows a different behaviour between female and male workers. The reduction in the number of workers between 2008 and 2012, as well as other figures in Table 1, suggest the research to be made distinguishing by gender and period.

The job destruction process in the period 2008-2012 has affected to men more deeply than women. The drop of jobs has focused on sectors such as building sector, industry and real state services at the beginning of the crisis. The duration and intensity of the economic crisis have spread the employment crush to other activities, but the effect has not been equal in all sectors. The gender composition of workers in terms of economic activities presents important dissimilarities, as percentages for big economic sectors show in Table 1 and Arellano (2010b) exposes in a more detailed version.

This gender difference in the number of observations and economic activities is extended to other factors. The figures for immigrant workers present a duality in the labour market participation. The group constituted by the native workers and those from the EU-15 and North America shows similar percentages by gender in both years. The rest of geographic areas provide relevant differences. The weight of men is higher than women for African people and those from Asia and Oceania, as well as for the rest of Europe in 2008. This relationship remains constant for the two former groups in 2012. However, those workers from the rest of Europe and the Caribbean 
and Latin America present a gender change in the labour market participation. The unequal effect on gender and economic activities seems to be reinforced with the comparison of the figures between 2008 and 2012.

Other differences between men and women appear in education (higher level for women) and labour market situation (self-employment option is more extended in the group of male workers).

Geographic variables suggest that female (occupied) workers are more likely to live in populous townships (as the values of Madrid and Barcelona also confirm), so labour market decisions of women may be more affected by size and agglomeration effects of population. However, the figures do not provide great composition changes between both years.

As Izquierdo, Lacuesta and Vegas (2009) comment, the labour market history of the worker also constitutes an important factor in the job selection process of the immigrant worker. Several indicators are considered, (a proxy of) experience, labour market mobility and characteristics of the last unemployment situation.

An indirect approximation of experience used in this study is the number of years since the date of the first active labour market relationship (i.e. as worker) with the Social Security. The use of age and experience as regressors could imply potential estimation problems due to the high correlation of both factors. This variable is considered an instrumental variable of the work experience. The period considered may also include unemployment spells and does not take into account work experience outside the Social Security files, as commented previously. Moreover, this variable is also an approximation of the duration of the assimilation process to the host country for foreign workers. The average period of experience proxy for men is above three years with respect to women.

Other factor to supplement the experience and analyse the influence of time persistence is the degree of labour mobility in the past. A set of three discrete variables are considered to measure the number of times the worker experienced any of the three labour market category before the current job. The results confirm a higher degree of mobility to self-employment for male workers, and women experienced temporary jobs frequently. These conclusions are similar for 2008 and 2012. 
TABLE 1

DESCRIPTIVE STATISTICS IN 2008 AND 2012

\begin{tabular}{|c|c|c|c|c|}
\hline & \multicolumn{2}{|c|}{2008} & \multicolumn{2}{|c|}{2012} \\
\hline & Women & Men & Women & Men \\
\hline \multicolumn{5}{|l|}{ Nationality } \\
\hline Spaniard & 91.52 & 89.63 & 89.59 & 90.25 \\
\hline EU-15 & 1.45 & 1.55 & 1.50 & 1.58 \\
\hline Africa & 0.73 & 2.27 & 0.89 & 2.13 \\
\hline North America & 0.04 & 0.03 & 0.05 & 0.04 \\
\hline The Caribbean and Latin America & 3.94 & 3.47 & 4.42 & 2.67 \\
\hline Asia and Oceania & 0.41 & 0.69 & 0.73 & 1.05 \\
\hline Rest of Europe & 1.91 & 2.36 & 2.82 & 2.28 \\
\hline \multicolumn{5}{|l|}{ Personal and job characteristics } \\
\hline Age (years) & 37.68 & 39.55 & 39.97 & 41.35 \\
\hline No education & 1.36 & 1.64 & 0.91 & 1.14 \\
\hline Primary education & 20.09 & 25.63 & 15.53 & 20.18 \\
\hline Secondary education - First stage & 35.84 & 39.41 & 35.29 & 39.48 \\
\hline Secondary education - Second stage & 30.98 & 25.97 & 29.46 & 26.93 \\
\hline University education & 11.73 & 7.36 & 18.80 & 12.28 \\
\hline Primary Sector & 2.03 & 3.60 & 2.05 & 5.00 \\
\hline Industry & 9.34 & 18.72 & 7.56 & 17.88 \\
\hline Building & 2.66 & 20.71 & 1.95 & 13.25 \\
\hline Service Sector & 85.97 & 56.96 & 88.43 & 63.87 \\
\hline \multicolumn{5}{|l|}{ Geographic characteristics } \\
\hline Township: 40,000 - 100,000 inhabitants & 13.31 & 12.89 & 15.48 & 14.96 \\
\hline Township: $100,000-250,000$ inhabitants & 15.66 & 15.22 & 15.40 & 14.63 \\
\hline Township: at least 250,000 inhabitants & 24.95 & 22.64 & 25.13 & 22.49 \\
\hline Madrid & 15.38 & 14.06 & 16.04 & 14.54 \\
\hline Barcelona & 13.86 & 12.63 & 13.67 & 12.66 \\
\hline Valencia & 5.51 & 5.61 & 5.27 & 5.40 \\
\hline Seville & 3.41 & 3.82 & 3.43 & 3.79 \\
\hline \multicolumn{5}{|l|}{ Labour market situation } \\
\hline Self - employed (SE) & 14.05 & 20.51 & 14.14 & 21.86 \\
\hline Employee - Permanent worker (PW) & 50.13 & 47.90 & 52.72 & 48.39 \\
\hline Employee - Temporary worker (TW) & 35.82 & 31.59 & 33.14 & 29.75 \\
\hline \multicolumn{5}{|l|}{ Labour market history } \\
\hline Experience proxy (years) & 14.38 & 17.70 & 16.60 & 19.80 \\
\hline Number of times SE previously & 0.18 & 0.30 & 0.22 & 0.35 \\
\hline Number of times PW previously & 1.02 & 1.00 & 1.45 & 1.40 \\
\hline Number of times TW previously & 7.24 & 6.33 & 9.29 & 8.11 \\
\hline Unemployment benefit & 16.83 & 17.13 & 21.45 & 23.61 \\
\hline Last unemployment spell (days) & 274.65 & 153.46 & 273.69 & 172.42 \\
\hline Number of observations & 323,661 & 445,000 & 318,021 & 385,098 \\
\hline
\end{tabular}

SOURCE: CSWH (Social Security). 
The selection process is also affected by the conditions of the last unemployment situation (if any). In order to control this effect, two variables are included: a binary variable indicating whether the individual had unemployment benefits, and the last unemployment spell measured in days, both before the current job. The use of unemployment benefits and the duration of the unemployment spell confirm that male workers suffered more deeply the effects of this crisis in the reference period than women did.

Table 2 shows the importance of the collective of self-employed workers by nationality in 2008 and 2012 and confirms the need for a more complex treatment in the study of labour market status. A first aspect is associated to the differences by gender. Men are more likely to be self-employed than women are, except for those whose citizenship belongs to Asia and Oceania. Among the rest of workers, two groups can be considered, because gender differences are very small for citizens from Africa, Caribbean and Latin America unlike the other nationalities.

The comparison of the figures about self-employment participation between 2008 and 2012 reflects an increase of the weight of this type of labour market relationship except for workers of the rest of Europe and women from North America. The moratorium established by the Spanish government in the period 2007-2009 on countries in the Eastern Europe incorporated to the EU, seems to affect the job selection process for the individuals of this group (specially male workers).

The change in absolute value is higher for men, another reason to control decisions about professional status by gender separately. This conclusion is confirmed by the figures of the OECD database about preferences for self-employment. The figures indicate that the percentage of men declaring they would prefer a self-employment job (if they were free to choose between self-employment and paid employment) is higher than that for women ${ }^{1}$.

This table also suggests the finding of Uwaifo Oyelere and Belton (2009) that workers from countries with self-employment rates higher than that of the home country tend to pursue self-employment at a higher rate than natives do (specially North America and the EU-15). However, the figures do not control for the effects of personal and environment background differences on this decision, as this paper tries to do.

${ }^{1}$ For further details about entrepreneurship in the OECD database, see web page: http://stats.oecd.org, section of Social Protection and Well-being. 
TABLE 2

SELF-EMPLOYED WORKERS BY NATIONALITY IN 2008 AND 2012

\begin{tabular}{|l|c|c|c|c|}
\hline \multirow{2}{*}{} & \multicolumn{2}{|c|}{2008} & \multicolumn{2}{c|}{2012} \\
\cline { 2 - 5 } & Women & Men & Women & Men \\
\hline Nationality & \multicolumn{2}{|c|}{} \\
\hline Spaniard & 14.51 & 21.38 & 14.69 & 22.65 \\
\hline EU-15 & 17.57 & 26.91 & 19.74 & 29.79 \\
\hline Africa & 5.14 & 5.67 & 5.68 & 7.18 \\
\hline North America & 28.57 & 34.03 & 27.92 & 36.31 \\
\hline The Caribbean and Latin America & 4.21 & 4.73 & 4.38 & 7.21 \\
\hline Asia and Oceania & 31.91 & 21.80 & 33.18 & 27.21 \\
\hline Rest of Europe & 8.95 & 20.21 & 6.61 & 13.35 \\
\hline
\end{tabular}

SOURCE: CSWH (Social Security).

\section{Modelling}

In order to assess and analyse the behaviour in terms of type of work between immigrants and natives, a type of discrete choice model is used. As indicated in the previous section, two possible states are considered for the occupied workers: selfemployment and paid employment. Behind the paid employment option, there are two contract situations that can be considered in the sample: fixed-term contracts and indefinite-duration contracts. There are several ways to analyse this multiple choice decision process. In this case, a multinomial logit model is implemented.

The conditional logit model is a generalized version of the so-called McFadden's choice model (McFadden, 1974) and the multinomial logit model. The structure of the database in this paper prevents the analysis of the complete labour market behaviour of the worker, because only the realization of the decision is observed. The database provides information on the characteristics of the position accepted, so the lack of decision-specific variables implies that both models will be equivalent.

These models are based on the utility maximization theory (random utility maximization model). Let $U_{i j}$ be the utility function of individual $i$ for the alternative $j$. Assuming linearity in the function, $U_{i j}$ is divided into an observable part $\left(V_{i j}\right)$ and a stochastic term $\left(\varepsilon_{i j}\right)$, collecting deviations that agents have with respect to the average agent behaviour due to random factors, $U_{i j}=V_{i j}+\varepsilon_{i j}$. If there are $J$ alternatives and $N$ individuals, the probability $P_{i j}$ that the individual $i$ chooses the alternative $j$ is equal to the probability that this option generates the maximum value in the utility function among the $J$ alternatives:

$$
P_{i j}=\operatorname{Pr}\left(U_{i j}>U_{i k}, k=1, \ldots, J ; k \neq j\right)=\operatorname{Pr}\left(\varepsilon_{i k}-\varepsilon_{i j}>V_{i j}-V_{i k}, k=1, \ldots, J ; k \neq j\right)
$$


Applied to the specific situation of the paper, the model considers that individual $i$ chooses among three options: self-employment, paid employment with a permanent contract and paid employment with a temporary contract. Assuming the error term is i.i.d. as a logistic distribution, the probability of choosing option $j$ for individual $i$ follows the expression:

$$
P_{i j}=\frac{\exp \left(V_{i j}\right)}{\sum_{k=1}^{3} \exp \left(V_{i k}\right)}
$$

Where $V_{i j}=\mathrm{X}_{i j}^{\prime} \beta_{j}+\mathrm{Z}_{i}^{\prime} \delta_{j}, \beta_{j}$ and $\delta_{j}$ represents two vectors of coefficients, specific for each alternative $j$, one for each explanatory variable used to collect the influence of any variable in the utility, $X_{i j}$ (set of alternative-specific variables) and $Z_{i}$ (set of individual-specific variables). The individual $i$ will maximize the expected utility giving each alternative.

The multinomial logit model depends on the independence of the irrelevant alternatives (IIA) assumption, so the choice between any pair of alternatives depends on the attributes of the two alternatives. As a first approximation, this assumption is accepted in this research. The final decision to accept the validity of the IIA property in this case is made by the reader.

The dependent variable relies on the worker's employment status, which takes the options described above. The estimates are divided by gender in order to control for the existence of information not included in the sample affecting the behaviour in the labour market between men and women differently, as occurs with family factors. This aspect may be relevant as Sanders and Nee (1996) point out, because the household's social relations may affect worker's labour market decisions, specially for immigrants.

The explanatory variables included in the models are divided into three big sets. The first set is constituted by personal and job characteristics. The personal variables are gender, age, education and nationality. The immigrant worker is classified into the following geographic areas: EU-15, the rest of Europe ${ }^{2}$, Africa, Caribbean and Latin America, Asia and Oceania, and North America. The main job characteristic considered in this paper is the economic activity.

The characteristics of economic activities allow that some sectors are more likely to use the figure of the self-employed worker than others. The information on economic activities is affected by a change in the classification of activities. There was a previous National Classification of Economic Activities (NCEA) for the year 1993, with slight modifications in 2003. Since 1993, the economy has undergone major changes, especially with regard to production processes, where new technologies

\footnotetext{
${ }^{2}$ The nationality classification created by the Social Security in the CSWH depends on the number of citizens of each country in the Social Security databases. Thus, the rest of Europe includes those individuals whose nationality corresponds to European countries outside the EU-15, unable to clearly distinguish among countries of the EU-27, EFTA and other countries outside these organizations.
} 
and Internet have a major impact on the economy. In addition, the service sector has diversified and grown, as occurs in the environmental sector. This process combined with the need for using comparable measures among countries required to standardize the classification of economic activities, which led to the definition of NCEA-2009, whose use began performing in 2008 with many limitations.

The changes were important and some large economic groups were affected by the new classification, especially finance and professional services, transport and communications and other services ${ }^{3}$. Similar economic sectors are considered in both classifications, but the great changes in methodology and the incorporation of new activities cannot be controlled perfectly. Therefore, these differences may affect the results, especially as comparison between 2008 and 2012 is done. Another reason to elaborate separated models for these two years is associated to this variable. The use of pooling data for the two years implies the creation of an aggregated economic variable indicator similar to that in Table 1, reducing the information level of the NCEA.

The second family of variables focuses on Geography. The relationship among regional (and local) institutions, labour market decisions, migrant behaviour and human capital is relevant, as Faggian and McCann (2009) suggest. The influence of spatial factors on the occupational decision-making of workers is considered using two variables, the province of the worker's residence and the size of the township. The first variable controls the importance of location (as a proxy of the formal and informal rules that guide social interactions in the area of the worker) and the second one considers size and agglomeration effects of population on labour market decisions.

A third group of variables is considered due to the last comments of Section 3. The existence of a severe duality in the labour market contract structure in Spain (Arellano, 2005) creates two groups of workers, people characterized by high job security and a set of workers who experience several labour market transitions. The occupational status is conditioned by the past labour market history of the worker. The effect of the past labour market history on this process is also a way to control the process immigrant becomes a naturalized citizen.

Several variables describing the past labour market history are included, apart from the approximation of experience mentioned in Section 3. The number of times the worker belonged to each alternative in the past is also used to capture previous labour market mobility. Three variables are included in the model indicating the number of times the worker experiences each labour market situation. Finally, two variables related with the last unemployment situation (if any) are incorporated to the analysis, a binary variable indicating the availability of unemployment benefits for the worker and the duration of this unemployment spell.

3 There is further information on the composition of these activities and other industries in the NCEA1993 and the NCEA-2009 in the INE website (http://www.ine.es/en/inebmenu/indice_en.htm\#35). 


\section{Results}

This research evaluates the characteristics promoting paid employment using a permanent contract (permanent employment) and a temporary contract (temporary employment) compared to the base option, which is self-employment. A subgroup of coefficient estimates are presented in Table 3 and Table 4, those for the nationality variables, taking the native workers as the base group. Jointly with any estimate, the standard deviation is given in brackets.

Both tables present the same structure, divided into four models. Model 1 provides only the estimates of the nationality binary variables by geographic areas. Model 2 includes also personal and job characteristics as regressors to those of Model 1. Model 3 incorporates also the geographic factors to the previous model, and Model 4 is constituted by all variables commented in Section 4. Each table shows estimates for men and women separately.

The use of estimates instead of marginal effects is motivated by the regressors. The marginal effect requires the use of specific values for the discrete variables. The large number of binary variables in the model reduce the appeal of the marginal effects, especially as the main interest of the paper focuses on the subgroup of nationality variables and the comparison among these four models.

The interpretation of the estimates arises mainly from a qualitative point of view, since the conclusions in quantitative terms are determined by the distribution of the error term. If the estimated coefficient has positive sign, the variable associated with that rate affects positively the probability of the outcome variable. If the coefficient is negative, this variable reduces the probability of that event. In some cases, the incorporation of nonlinear effects requires the combination of several estimated coefficients in order to know the impact, but the conclusions of the result with respect to the sign are done in the same way.

The results associated to nationality groups corresponding to 2008 appear in Table 3. The estimates of Model 1 for men suggest the existence of differences between natives and immigrant workers in the probability of being employed with a permanent contract with respect to self-employment. Moreover, there are relevant dissimilarities among geographic areas.

The European male workers (regardless the belonging to the EU-15 or not) are more likely to accept the self-employment situation compared with permanent employment than natives. However, the male workers from Africa seem to show a clear propensity to join the group of employees. The behaviour of workers from the Caribbean and Latin American countries is similar to that shown by the workers from Africa, but the effect is the highest in absolute value of the zones considered. Those men from Asia and Oceania show negative and significant values as the European workers, although the effect is the smallest of all geographic areas.

The duality between self-employment and temporary employment has the same qualitative results as the previous one for the collectives from Africa and America. The workers from Asia and Oceania, and the rest of Europe change their propensity 
of accepting self-employment. These groups are more like to have a temporary contract than native workers. Only those from the EU-15 do not present relevant dissimilarities with respect to the reference group.

The estimates for women also confirm the existence of heterogeneous behaviour in the selection of occupational status. In the model between the self-employment and the permanent employment alternatives, the qualitative conclusions are similar to those presented previously, except for the rest of Europe. Women from this area are more likely to select permanent employment than self-employment, compared to natives, although the effect is the lowest of all groups in absolute value.

The personal and job characteristics (Model 2) do not generate important movements in the comparison between self-employment and permanent employment. However, there are changes when temporary employment is considered for men. Those workers from the EU-15 show positive and significant estimates and the coefficient of North America reduces its statistical significance. The effect is smaller in absolute value for Africa and the rest of Europe. The most relevant change for women focuses on the group of the rest of Europe, whose estimation is not statistically significant.

The use of geographic variables as regressors (Model 3) reinforces the (qualitative) effects of nationality on professional preferences suggested in the previous model, regardless the gender of the worker.

The variables related with the past labour market history confirm the effects of the nationality groups in the model between self-employment and permanent employment for men.

The differences between Model 1 and Model 3 for women are mitigated in Model except for those from the EU-15 (this binary variable shows a non-significant estimate), suggesting that there are not dissimilarities in the occupational status among all workers of the EU-15. The particular behaviour of the women from the rest of Europe in Model 2 and Model 3 is eliminated and the estimate seems to confirm the conclusion of Model 1.

The selection between self-employment and temporary employment in Model 4 provides further differences with respect to the rest of models. The male workers from the EU-15 are more likely to be self-employed and the estimate is statistically different from zero. Moreover, the effect for the African workers is negative, but the value reduces between $23 \%$ and $36 \%$ the results of the previous models. This behaviour is also observed for the workers from the Caribbean and Latin America, although the estimate is positive. The results for the two last groups (Asia and Oceania, and the rest of Europe) change from Model 4 to the rest of models. These two groups of workers are more likely to consider self-employment instead of temporary employment.

In the comparison between self-employment and temporary employment, the female workers also show differences in Model 4. The conclusions are similar to those exposed for women in the model between self-employment and permanent employment, confirming the similar behaviour between natives and those from the EU-15. 


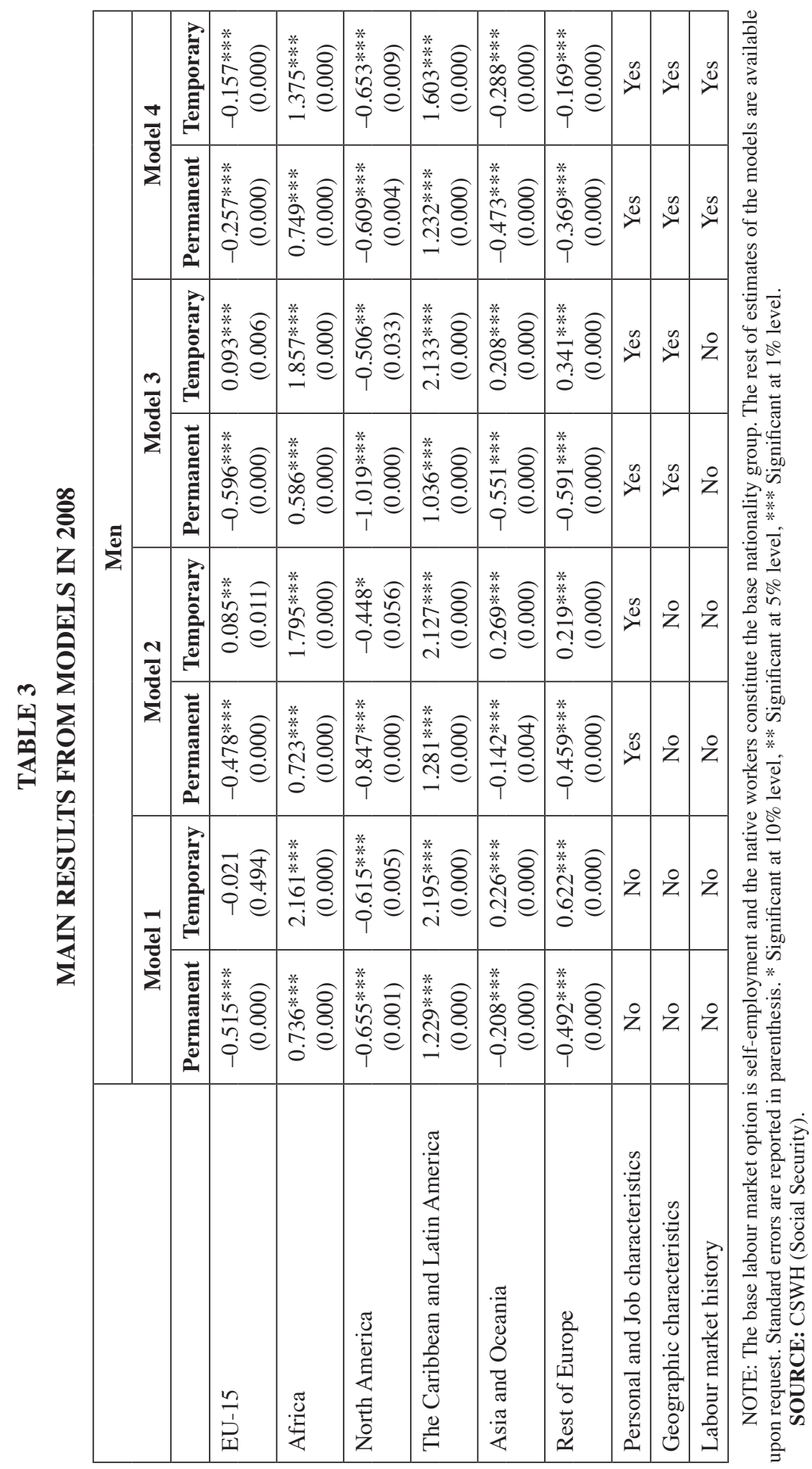




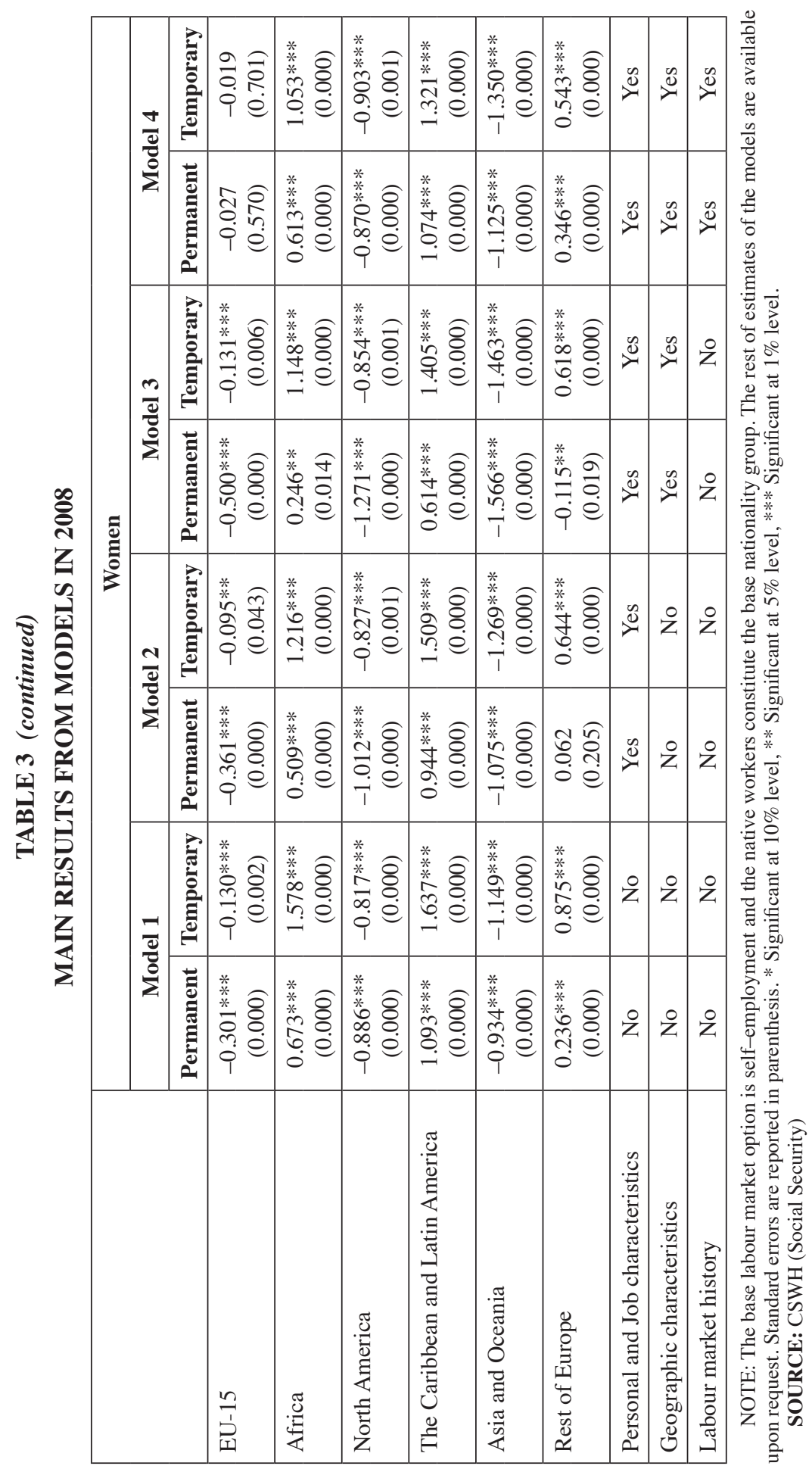


Table 4 presents the results corresponding to 2012. The labour market situation in 2012 differs from that context in 2008, not only for immigrant but also native workers.

The estimates obtained in Model 1 between self-employment and permanent employment share similar qualitative results as those presented in 2008 for men, except for the rest of Europe, whose estimate suggests these workers are more likely to get an indefinite duration contract. The results for women are similar to those obtained in 2008, except for the women from the rest of Europe, whose effect is intensified and goes in the same direction as their male partners. A plausible explanation of their change of decision may be related with the omission of the moratorium established by the Spanish government in the period 2007-2009, as commented in Section 2.

As temporary employment is considered, the estimate for men from the EU-15 is statistically significant, as it also occurs in the group of female workers for both years, so they are less likely to get a fixed-term contract than the self-employment option. By contrast, the male workers from Asia and Oceania do not show a special preference between these two options in 2012, unlike in 2008. There are not relevant differences in this selection process for women between 2008 and 2012.

The estimates of Model 2 for the duality between permanent employment and self-employment in 2012 confirm the conclusions elaborated for 2008. The exception is the collective of the workers from the rest of Europe. These people have changed their previous criteria, so both men and women are more likely to get an indefinite duration contract than the self-employment situation if the moratorium is eliminated.

The comparison between self-employment and temporary employment in Model 2 in 2012 also presents particular characteristics that differ from those of Table 3. The behaviour of male workers from the EU-15 is similar to the previous duality, emphasizing the selection of self-employment, as it also occurs for their female partners. The male workers from Asia and Oceania also share this conclusion. There are not relevant qualitative changes for women in this model with respect to Model 1.

The duality between self-employment and permanent employment in Model 3 shows the most relevant difference for the collective from the rest of Europe. Both male and female workers are more likely to get an indefinite duration contract, and these estimates are statistically significant. The changes between 2008 and 2012 are similar in the comparison between self-employment and temporary employment to those of Model 2, affecting to male workers from the EU-15, as well as Asia and Oceania, who are more likely to select a self-employment option instead of a fixedterm contract.

The estimates of Model 4 shares the same qualitative characteristics and differences between the two reference years as those presented in Model 3 for men in the selection between self-employment and permanent employment. The results for female workers in 2012 suggest significant differences between natives and their partners from the EU-15, unlike the year 2008, and the positive estimate of the rest of Europe in 2012 more than doubles the value in 2008. 
The comparison between self-employment and temporary employment provides similar qualitative results in both reference years, except for men from the rest of Europe. This last group is more likely to get a fixed-term contract than selfemployment in 2012, following the behaviour of workers from Africa, and Caribbean and Latin America.

With respect to the female workers, the most relevant change affects to women from the EU-15, who presents significant differences to native women in this duality, and they are more likely to select self-employment.

Unlike the conclusions derived from models in 2008, the results of Model 4 in 2012 do not show important qualitative differences with respect to those of previous models in this reference year. However, there are quantitative changes in the effect of nationality on the outcome variable between Model 3 and Model 4, especially for men. The movements between both models usually reinforce the interest for the self-employment option compared to temporary employment, and the preference of permanent employment instead of self-employment for all groups but those from Asia and Oceania.

The comparison of the results between 2008 and 2012 suggests robustness in the (comparative) results between native and immigrant workers only in general terms. There exist changes in the selection of professional position for particular subgroups of immigrants. These movements may be caused mainly because the workers are conditioned by two different economic situations and histories inside a context of crisis. 


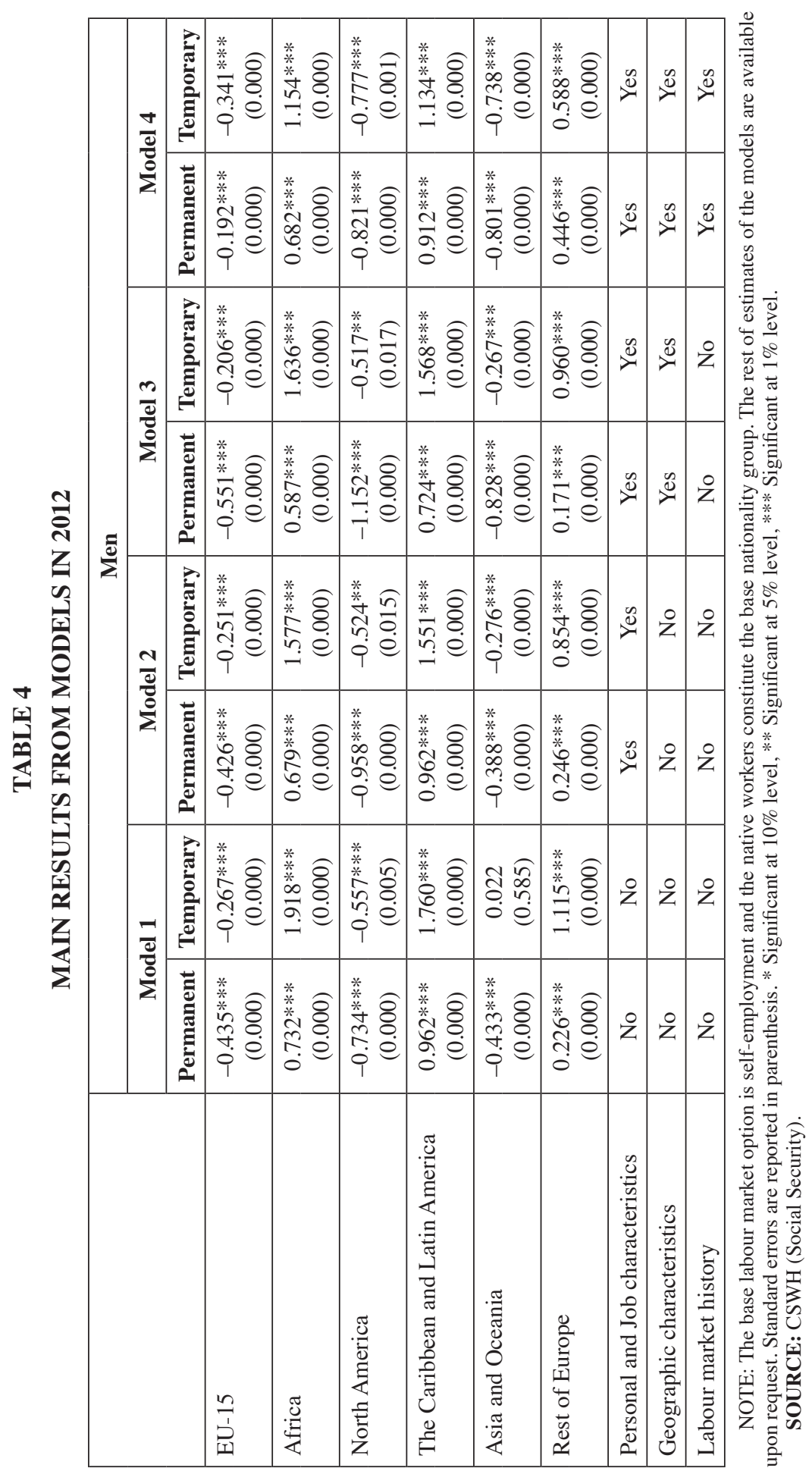




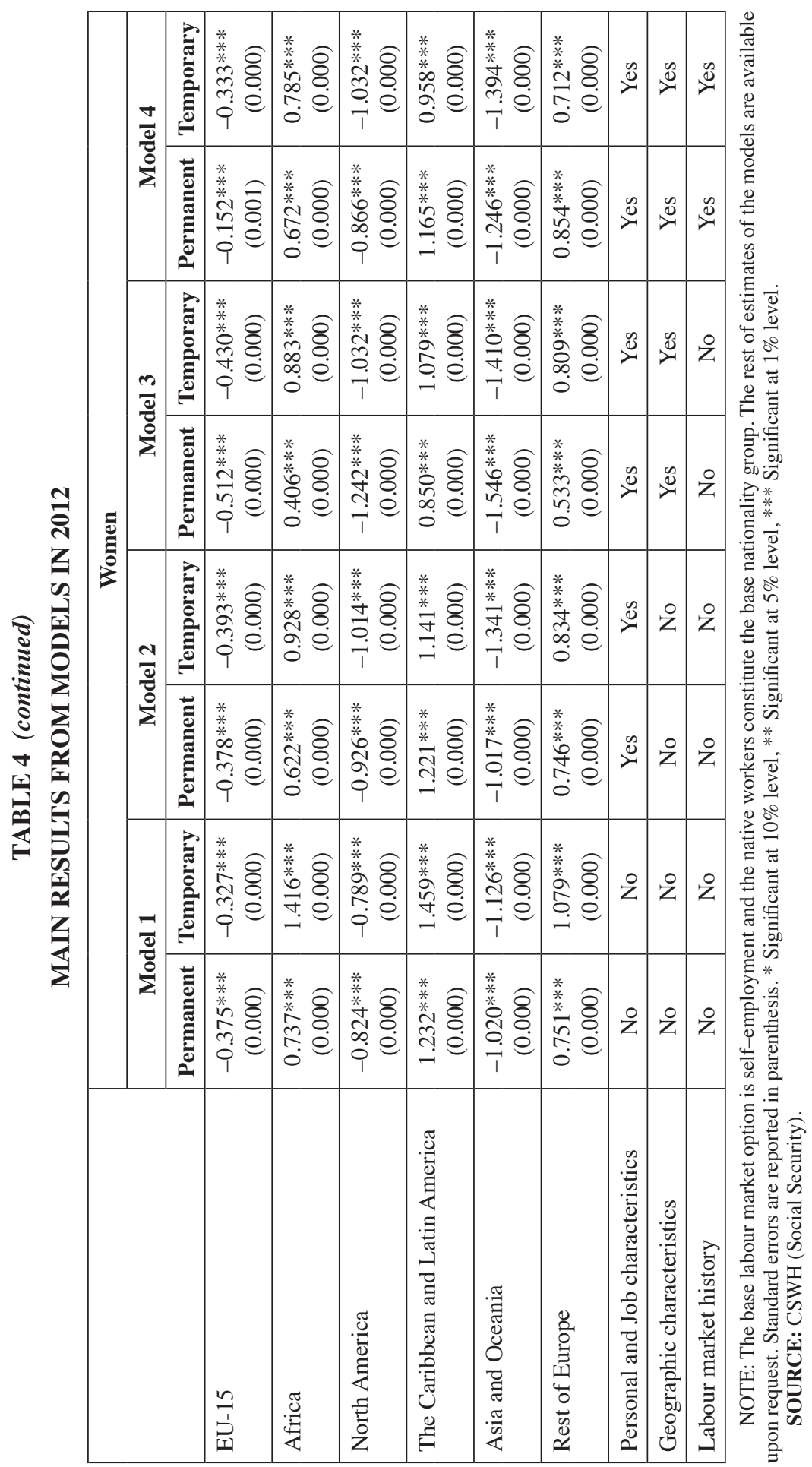




\section{Concluding remarks}

This paper describes the characteristics that qualify to self-employed workers, distinguishing by nationality. It also tries to determine whether there are significant dissimilarities in the labour market decisions considering the influence of internal (personal and labour market characteristics of the worker) and external (geographic and economic environment) factors, affecting the type of employment performed and finally find, if any, which are the differential elements.

The results confirm the existence of a different behaviour between immigrant and native workers in terms of occupational status (mainly between self-employment and paid employment). The estimates between permanent employment and temporary employment suggest the workers consider the selection of indefinite duration contract versus fixed-term contract as relevant as the decision for the previous dichotomy. Moreover, the immigrant workers do not constitute a homogeneous group in this professional aspect.

Taking into account the cultural differences, workers are conditioned by a difficult economic situation. The economic crisis has resulted in a worsening of working conditions that forced immigrants especially (one of the most affected collectives) to adapt to new professional opportunities. The institutional background and supplementary information on these topics are also provided to know the context between the self-employment and paid employment.

This study considers the need for taking into account the relation between immigrants and labour market in Spain, and the combination of the "culturalist" factor (where nationality is a remarkable instrument in the entrepreneurial initiative process) with the "structuralist" factor (the elements in the host country influence the choice of occupation of the immigrant worker).

Comparing a self-employed worker with an employee in 2008, and considering as main variable the nationality of the worker and the model with all the available regressors, those men from North America, Asia and Oceania, and Europe select the first option. The group of female workers who were more likely to be a selfemployed worker is focused on North America, Asia and Oceania.

After four years of economic crisis, the sets of immigrant people who were more likely to be a self-employed worker than native workers in Spain are citizens of countries belonging to North America, Asia and Oceania, and the EU-15, regardless of the gender of the worker. These areas include a great part of the developed countries and those with high levels of entrepreneurship. This result combined with the OECD databases may confirm the finding of Uwaifo Oyelere and Belton (2009) that workers from countries with self-employment rates higher than that of the home country tend to pursue self-employment at a higher rate than natives do.

The existence of institutional restrictions, as the moratorium established by the Spanish government in the period 2007-2009 on the last countries in the Eastern Europe incorporated to the EU, seems to affect the job selection process for workers from the rest of Europe. These comments reinforce the importance of the 
"structuralist" and the "cultural" factors in the selection process of the occupational status.

The results also confirm the complexity of the self-employment situation, especially in a context of economic crisis and a higher cultural diversity in the labour market unknown in the recent history of Spain. Moreover, these factors may be more relevant because the conclusions focus on workers belonging to the formal economy, given the use of administrative data from the Social Security. Therefore, behaviour of immigrants and natives in the Spanish labour market, especially in a negative economic environment, demands further research.

\section{References}

[1] ARELlanO, A. (2005): "Do Training Programmes get the unemployed back to work? A look at the Spanish experience". Working Paper 05-25, Economic Series 05, Universidad Carlos III, Madrid.

[2] ARELlANO, A. (2010a): "Inmigrantes y periodo de residencia: descriptiva de la asimilación en materia laboral entre España y la Comunidad de Madrid". Estudio Económico 09-2010, Fedea, Madrid.

[3] ARELLANO, A. (2010b): "Pautas de la inmigración en el mercado de trabajo: comparativa sectorial y espacial en el cambio de ciclo". Estudio Económico 14-2010, Fedea, Madrid.

[4] BORJAS, G. (1986): “The self-employment experience of immigrants". The Journal of Human Resources, 21 (4), pp. 485-506.

[5] BRUNET, I. and A. ALARCÓN (2005): ¿Quién crea empresas? Redes y empresarialidad. Talasa, Madrid, Spain.

[6] FAGGIAN, A. and P. MCCANN (2009): "Human capital and regional development", in R. Capello and P. Nijkamp (eds.), Handbook of regional growth and development theories, pp. 133-151. Edward Elgar Publishing, Cheltenham, UK.

[7] IZQUIERDO, M.; LACUESTA, A. and VEGAS, R. (2009): "Assimilation of immigrants in Spain: A longitudinal analysis”. Labour Economics, 16 (6), pp. 669-678.

[8] LACUESTA, A. and PUENTE, S. (2010): "El efecto del ciclo económico en las entradas y salidas de inmigrantes en España". Working paper No. 1016, Bank of Spain.

[9] LIGHT, I. (1972): Ethnic Enterprise in America. University of California Press, Berkeley/London.

[10] MCFADDEN, D. (1974): “Conditional logit analysis of quantitative choice behaviour”, in P. Zatembka (ed.), Frontiers in Econometrics, pp. 105-142. Academic Press, New York.

[11] SÁNCHEZ-MORAL, S.; MÉNDEZ, R. and ARELLANO, A. (2014): “Creative economy and employment quality in large urban areas in Spain”, Urban Geography, 35 (2), pp. 264-289.

[12] SANDERS, J. M. and NEE, V. (1996): "Immigrant Self-Employment: The Family as Social Capital and the Value of Human Capital", American Sociological Review, 61 (2), pp. 231-249. 
[13] SOLÉ, C.; PARELLA, S. and CAVALCANTI, L. (2007): El empresariado inmigrante en España. Colección Estudios Sociales No. 21, Obra Social "La Caixa", Fundación "La Caixa".

[14] UWAIFO OYELERE, R. and BELTON, W. (2009): "Coming to America: Does immigrant's home country economic status impact the probability of self-employment in the U. S.?". Discussion paper No. 4178, IZA, Bonn, Germany.

[15] WALDINGER, R.; ALDRICH, H. and WARD, R. (1990): "Opportunities, Group Characteristics, and Strategies", in R. Waldinger et al. (eds.), Ethnic Entrepreneurs. Immigrant Business in Industrial societies. Sage, London, UK.

[16] ZHOU, M. (1992): Chinatown. Temple University Press, Philadelphia, US. 